\title{
Rekayasa Perangkat Lunak Performance Indicator dalam Penentuan Penilaian Karyawan dengan Metode Simple Additive Weighting
}

\author{
Yansen $^{1}$, Zifa Fauziah ${ }^{2}$, Yesica Wisda Ananda ${ }^{3}$, Yulianti ${ }^{4}$ \\ Teknik Informatika, Universitas Pamulang, Tangerang Selatan, Indonesia \\ e-mail: ${ }^{1}$ yansentannizar@gmail.com, ${ }^{2}$ zifafauziah4@gmail.com, ${ }^{3}$ yesicawisda@ gmail.com \\ 4yulianti@unpam.ac.id
}

Submitted Date: October $10^{\text {th }}, 2020$

Revised Date: October $09^{\text {th }}, 2020$
Reviewed Date: October $08^{\text {th }}, 2020$

Accepted Date: October $31^{\text {st }}, 2020$

\section{Abstract}

Employee appraisal is an important factor in the development of a company effectively and efficiently because employee appraisal is one of many indicators in measuring the background of human resources system in the company. Determining the right indicators of human resources can motivate better employee performance. To support this kind of system, a software engineering with Performance Indicator system is needed and data collection techniques by direct observation and data documentation are needed. Application of engineering Key Performance Indicator software for employee performance appraisal using the Simple Additive Weighting method can result in the efficiency of the assessment process in determining the quality of an employee's performance. as well as assisting employees in knowing the results of performance evaluation, and making it easier for supervisors to obtain reports on sales performance ratings so that superiors can and make determine the amount of salary, commision and bonus increases more precisely and efficiently.

Keywords: Performance Indicator; Simple Additive Weighting; Appraisal; Employee

Abstrak

Penilaian karyawan adalah faktor penting dalam perkembangan sebuah perusahaan secara efektif dan efisien karena dengan penilaian karyawan ini menjadi salah satu dari banyak indikator dalam tolak ukur pada latar belakang sumber daya manusia yang ada dalam perusahaan. Penentuan indikator atas sumber daya manusia yang tepat dapat memotivasi pelaksanaan kerja karyawan yang lebih baik dan tepat. Dalam mendukung hal ini, sangat dibutuhkan sebuah rekayasa perangkat lunak dengan sistem Performance Indicator dan dengan teknik pengumpulan data secara observasi langsung dan dokumentasi data. Penerapan rekayasa perangkat lunak Key Performance Indicator untuk penilaian kinerja karyawan mengunakan metode Simple Additive Weighting dapat menghasilkan efisiensi waktu proses penilaian dalam penentuan kualitas kinerja seorang karyawan. serta membantu para karyawan dalam mengetahui hasil evaluasi kinerja, dan mempermudah atasan memperoleh laporan hasil kinerja danl aporan lainnya sehingga atasan dapat menentukan besaran kenaikan gaji, komisi dan bonus dengan lebih tepat dan efisien.

Kata Kunci: Performance Indicator; Simple Additive Weighting; Penilaian; Karyawan

\section{Pendahuluan}

Sumber daya manusia adalah salah satu aset perusahaan yang cukup berpengaruh dalam perkembangan perusahaan. Setiap sumber daya manusia dalam setiap departemen atau bagian tentunya memegang peranan masing-masing untuk memajukan sebuah perusahaan. Untuk mencapai tujuan tersebut, perusahaan membutuhkan karyawan yang memiliki kinerja yang baik. Penilaian kinerja karyawan menjadi faktor penting untuk memajukan suatu perusahaan secara efektif dan efisien. Melakukan scoring terhadap pekerjaan sangat penting karena adanya pelaksanaan penilaian akan membuat kerja karyawan menjadi berkembang. Dan cara yang dapat digunakan perusahaan untuk menentukan kualitas kinerja karyawan secara lebih terarah dan sistematis adalah dengan menerapkan Performance Indicator (Soemohadiwidjojo, 2015). 
Performance Indicator digunakan untuk bisa membantu memberikan transparansi kepada setiap karyawan dan hasil dari yang telah tercapai oleh setiap karyawan (Moeheriono, 2012). Dengan penilaian yang sistematis dan terarah, perusahaan dapat mempertimbangkan penentuan besaran kenaikan gaji untuk setiap karyawan secara tepat sehingga karyawan dapat meningkatkan kinerjanya.

Guna mengefisiensi waktu proses penilaian Performance Indicator yang masih menggunakan Microsoft Excel, maka akan dibuat sebuah sistem rekayasa perangkat lunak Performance Indicator kinerja karyawan dengan menerapkan sistem penunjang keputusan (Latif, 2018). Sistem Penunjang Keputusan (SPK) termasuk teknologi informasi ditujukan untuk membantu pekerjaan dengan menyediakan informasi dan melakukan berbagai tugas yang berhubungan dengan pengolahan informasi (Hanum \& Saifudin, 2019). SPK menyediakan informasi tentang opsi yang dapat dipilih dengan urutan tertentu, sehingga mempermudah pengambil keputusan mempertimbangkannya.

Metode Simple Additive Weighting sebagai salah satu metode dalam sistem pendukung keputusan yang paling banyak dikenal dan dipakai. Metode Simple Additive Weighting mampu mendukung penetapan pilihan terbaik dari beragam pilihan-pilihan yang telah ditetapkan (Sari \& Febrina, 2018).

Oleh karena itu, dalam pembuatan sistem ini menggunakan metode Simple Additive Weighting dengan menetapkan setiap kriteria dan pilihan, metode Simple Additive Weighting akan memberikan nilai referensi yang tepat sehingga memudahkan manager untuk mengetahui kinerja dari setiap kariyawan dan membantu manager dalam evaluasi kinerja karyawan melalui pengukuran Performance Indicator. Kelemahannya terletak pada kebenaran dan ketepatan hasil metode Simple Additive Weighting yang bergantung sepenuhnya pada keakuratan data yang dimasukkan namun karakteristik penentuan cakupan kriteria yang luas dan harus dinamis pada metode Simple Additive Weighting dapat menyusutkan keakuratan hasil.

Penelitian, dengan judul Sistem Pendukung Keputusan Menggunakan Metode Simple Additive Weighting (SAW) Untuk Menetukan Penerimaan Karyawan Pada CV.Green Advertising, menjelaskan penggunaan sistem pendukung keputusan penerimaan karyawan dengan Simple Additive Weighting, diharapkan dapat membantu mendukungdalam pengambilan keputusan karyawan dengan kriteria dari pendidikan, pengalaman dalam berkerja, keahlian setiap individu, kelengkapan dan kecocokan berkas.Hasil dari Sistem Pendukung Keputusan Penerimaan Karyawan menggunakan sistem komputer dan sistem manual memberikan pilihan alternatif yang sama (Rinianty \& Sukardi, 2018).

Untuk mengimbangi kelemahan tersebut, penulis membuat perangkat lunak berbasis PHP dan $M y S Q L$ yang dapat mengintegrasi data-data seperti pengaksesan akun, pemasukan data yang berdasarkan hak akses akun, pencarian data, otomatisasi dalam perhitungan peringkat karyawan serta penyajian laporan peringkat kinerja karyawan yang diintegrasikan dengan database. Sehingga diharapkan dapat mengefisiensi proses penilaian Key Performance Indicator yang menggunakan metode Simple Additive Weighting sebagai pendukung pengambilan keputusan mengenai kualitas karyawan.

Untuk mengimbangi kelemahan tersebut, dalam membuat perangkat lunak berbasis PHP dan $M y S Q L$ yang dapat mengelola data-data dari pada setiap indikator-indikator yang ada. Sehingga diharapkan dapat mengefisiensi proses penilaian Performance Indicator yang menggunakan metode Simple Additive Weighting sebagai pendukung pengambilan keputusan mengenai kualitas penilaian dari seorang karyawan.

Maka dari itu, dibuatlah sebuah Rekayasa Perangkat Lunak Key Performance Indicator karyawan menggunakan metode Simple Additive Weighting berbasis PHP dan MySQL yang diharapkan dapat memberikan proses penilaian yang efisien serta memberikan nilai referensi yang tepat saat pengamatan untuk evaluasi kinerja setiap karyawan.

\section{Metodologi}

\subsection{Metode Penelitian}

Metode rekayasa perangkat lunak yang digunakan adalah prototyping (Wicaksono, 2017). Perangkat Prototyping merupakan bagian dalam produk yang mengemukakan logika maupun tampilan fisik antarmuka eksternal. Tahapan langkah requirement prototype, adalah sebagai berikut:

a. Analisis kebutuhan user, perekayasa perangkat lunak dan pengguna sistem melakukan dialog di mana pengguna sistem membreitahukan tentang apa keperluan sistem yang user inginkan. 
b. Membangun prototype, perekayasa perangkat lunak dengan membuat prototype dari sistem yang telah diberitahukan oleh pengguna sistem.

c. Menyesuaikan prototype dengan harapan user, perekayasa perangkat lunak dengan menanyakan kepada pemilik sistem tentang prototype yang dibuat, apakah sesuai atau tidak dengan keinginan dari user.

d. Membangun sistem yang baru, perekayasa perangkat lunak dengan menggunakan perangkat prototype yang dibuat untuk sistem yang lebih baru.

e. Melakukan Pengujian (testing), pengguna melakukan proses test kepada Software yang direkayasa. Pengujian perangkat lunak merupakan tahap yang harus dilalui untuk menjamin kualitas sistem/aplikasi yang dikembangkan (Pratala, Asyer, Prayudi, \& Saifudin, 2020). Pengujian merupakan suatu rangkaian aktivitas yang terencana dan sistematis untuk menguji atau mengevaluasi kebenaran fungsi aplikasi berdasarkan desain kasus uji (test case) yang spesifik (Yulistina, Nurmala, Supriawan, Juni, \& Saifudin, 2020).

f. Mencocokan dari keinginan user, perangkat lunak dibuat dengan mencocokan dari keinginan user dan kebutuhan sistem.

g. Observasi Mempelajari proses dari data diterima dan diproses serta menemukan permasalahan yang ada pada siklus tersebut untuk kemudian dicarikan solusinya.

h. Analisis dan Pengumpulan Data Mengumpulkan dan mempelajari data aspek Performance Indicator yang ada.

\subsection{Metode Analisis Data}

Analisa data yang digunakan adalah analisis data kualitatif, adalah suatu analisa yang didasari atas data yang diperoleh, kemudian diproses sebagai sebuah kesimpulan (Utama, 2016). Terdapat berbagai macam pendekatan untuk menganalisa suatu sistem, semua pada dasarnya memiliki hasil akhir yang sama, yaitu mengerti dari sistem yang berjalan ataupun sulit kemudian dapat melakukan perubahan dengan beberbagai cara. Dan hasil peruhaan tersebut dapat berupa berbagai subsistem baru, maupun komponen baru atau serangkaian Transformasi baru dan lain-lain (Kadir, 2017). Tujuan utamanya yaitu untuk memperbaiki sistem yang terdapat dalam organiasi melalui penerapan software yang dapat membantu karyawan untuk mencapai setiap tugasnya dengan mudah dan efisien (Mulyani \& sri, 2016).

\subsection{Analisa Sistem Berjalan}

Berdasarkan hasil observasi, karyawan menyiapkan dan menyerahkan dokumen pendukung penilaian kepada supervisor. Supervisor menerima dan memeriksa dokumen pendukung penilaian karyawan, kemudian supervisor memasukan data pada dokumen pendukung penilaian ke masing-masing file excel Performance Indicator karyawan dan menyerahkan ke manager dalam bentuk tercetak. Manager menandatangani file excel Performance Indicator karyawan, lalu supervisor membuat laporan penilaian Performance Indicator masing masing sales dan laporan rekapitulasi ranking kinerja, serta membagikan laporan tersebut ke karyawan dan manager.

\subsection{Analisa Sistem Usulan}

Berdasarkan sistem yang telah berjalan di atas dan memahami setiap permasalahan yang ada, maka penulis membangun sebuah ide dan solusi untuk menyelesaikan dari masalah. Dan sistem yang diajukan ini mempunyai tujuan, agar mendapatkan efisiensi waktu proses penilaian dalam penentuan kualitas kinerja karyawan, serta membantu para karyawan dalam mengetahui hasil evaluasi kinerja, dan mempermudah atasan memperoleh laporan hasil kinerja karyawan.

Unified Modeling Language yang berarti bahasa pemodelan standar. Setiap model yang dibangun harus saling terhubung satu dengan lainnya dengan mencontoh standar yang sudah ditetapkan, sehingga menceritakan konteks yang ingin dibuat.

\subsubsection{Activity Diagram}

Activity diagram mendeskripsikan setiap aksi padasuatu sistem, proses berjalan, maupun menu pada Software. Diagram ini menjelaskan setiap aksi yang dapat sistem lakukan, dan bukan yang dapat user perbuat.

Activity diagram di bawah ini menjelaskan tentang setiap langkah kerja dan siapa yang memiliki kewajiban atas masing-masing aktifitas seperti pada gambar 3 berikut ini: 


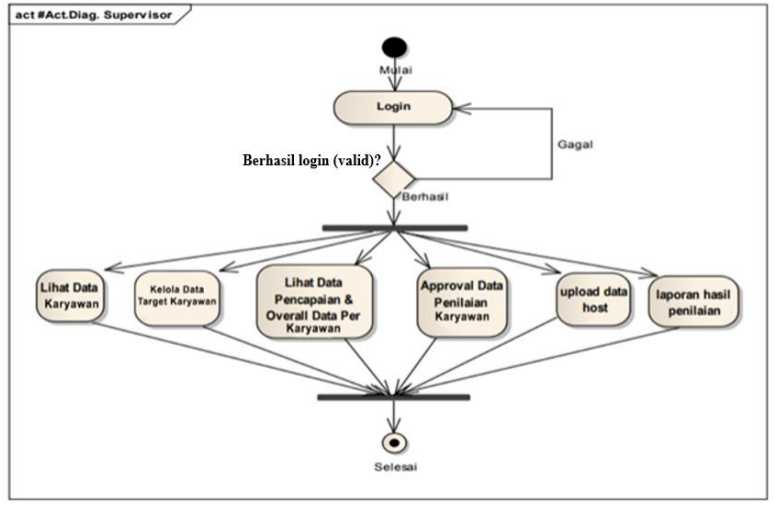

Gambar 1Activity diagram usulan untuk supervisor

Pada activity diagram ini, seorang supervisor dapat melihat data karyawan, mengelola data target dan mengecek kinerja setiap karyawan, melakukan approval data penilaian yang dikirimkan sales, serta dapat melakukan perhitungan kinerja karyawan dan menampilkanlaporan.

\subsubsection{Use Case}

Use case diagram adalah suatu diagram yang dipakai dan dibuat untuk mewujudkan sebuah sistem ke dalam wujud grafis (Muslihudin \& Oktafianto, 2016). Use case diagram sendiri memiliki tujuan untuk membuat penggambaran dari suatu sistem. dan hubungan antara sistem dengan actor. Use case diagram di bawah menunjukan diagram yang mendeskripsikan kebutuhan sistem dari cara pikir user, dan menunjukkan relasi-relasi yang terjadi antara actor dengan use case dalam sistem

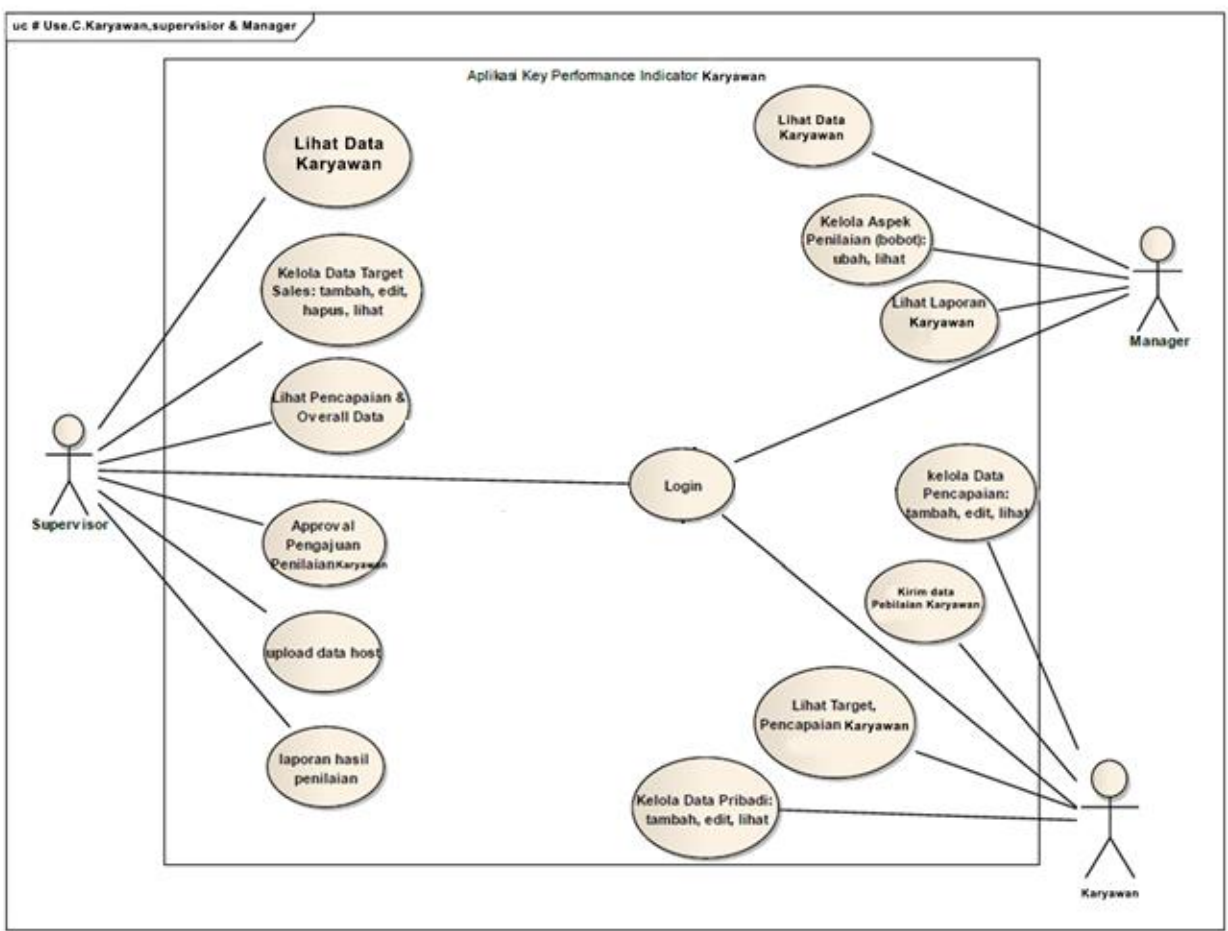

Use case diagram Key Performance Indicator kinerja Karyawan

Pada use case ini terdapat tiga aktor yaitu supervisor, manager dan karyawan itu sendiri, sebelum ketiga aktor memulai aktifitas pada perangkat lunak, tiap-tiap aktor harus melalui proses login, dan proses login tersebut akan membawa user ke halaman sesuai hak akses akunnya

\section{Hasil dan Pembahasan}

Spesifikasi perangkat keras dan perangkat lunak yang digunakan adalah sebagai berikut:

A. Spesifikasi Perangkat Keras (Hardware)
Hardware adalah perangkat keras yang merupakan berbagai alat yang terlihatm dapat di sentuh dan saling terhubung dengan computer, Monitor, harddisk, dan mouse adalah contoh perangkat keras. Perangkat keras yang digunakan adalah laptop Lenovo Ideapad S340dengan spesifikasi sebagai berikut:

1. Processor IntelIntel Quad-Core i5-8265U

2. Memory Ram $8 \mathrm{~GB}$

3. Memory Hard Disk 500 GB 
B. Spesifikasi Perangkat Lunak (Software)

Software atau perangkat lunak adalah instruksiinstruksi yang ditujukan kepada computer agar dapat melaksanakan tugas sesuai kehendak pemakai. Dan software ini sendiri memiliki peran yang penting untuk menghubungkan user, hardware, dan aplikasi yang dibuat.

Spesifikasi software yang akan digunakan adalah sebagai berikut:
1. SistemOperasi Windows10 Enterprise64-bit
2. Bahasa PemprogramanPHP
3. Browser GoogleChrome
4. Database $M y S Q L$

Dalam membuat perangkat lunak ini digunakan bahasa pemrograman PHP karena open source sehingga mudah untuk mengembangkannya sesuai dengan yang dibutuhkan dalam pembuatan perangkat lunak, selain itu Bahasa pemrograman PHP juga multiplatform di mana sangat cocok untuk dipakai di berbagai komputer dan segala jenis sistem operasi dan bisa dihubungkan dengan berbagai jenis database, salah satunya yaitu MySQL yang menjadi server pada perangkat lunak ini. MySQL menjadi server database karena penggunaannya yang mudah serta bersifat open source juga seperti bahasa pemrograman PHP yang bisa menambahkan, menghapus, mengubah, menyortir, dan melakukan operasi lainnya untuk memodifikasi data, value, atau visual. Oleh sebab itu juga kami menggunakan bahasa pemrograman PHP karena merupakan scripting server-side, maka bahasa pemrograman ini nantinya program akan diproses oleh server.

Implementasi merupakan suatu aktifitas terakhir dari suatu proses implementasi sistem baru yang akan digunakan secara menyeluruh. Implementasi merupakan penerapan rekayasa perangkat lunak yang terlihat dan dapat digunakan oleh pengguna perangkat lunak tersebut. Berikut implementasi pada perangkat lunak Performance Indicator untuk penilaian karyawan menggunakan metode Simple Additive Weighting:

1. Form tambah user ID

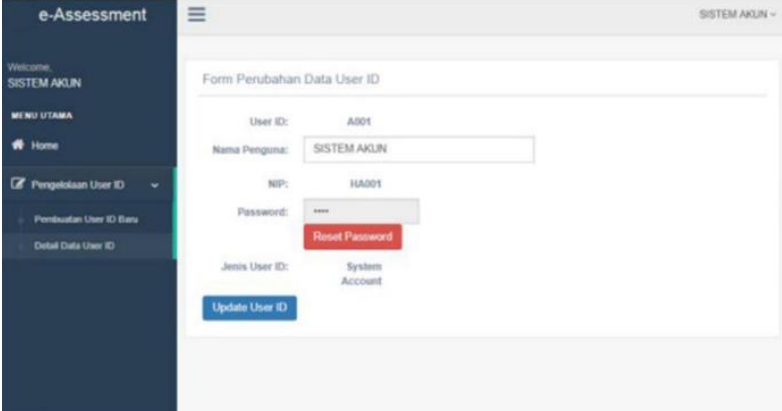

Gambar 7. Tampilan tambah user id

Tampilan halaman user id ini menampilkan data user yang ingin diubah dan yang hanya bisa diubah yaitu nama pengguna, dan reset password. Untuk mengkonfirmasi perubahan cukup hanya dengan menekan tombol update user id.

\section{Form tambah karyawan}

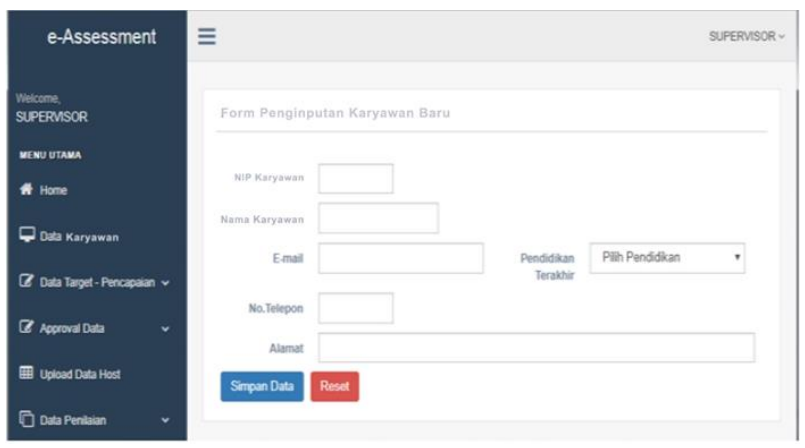

Gambar 8. Tampilan tambah karyawan

Tampilan halaman tambah data karyawan untuk memberikan informasi singkat seputar profil personil karyawan. Pada halaman ini juga sebagai informasi total karyawan yang masuk ke dalam penilaian Performance Indicator dari perusahaan ini.

\section{Form hasil penilaian |(Laporan)}
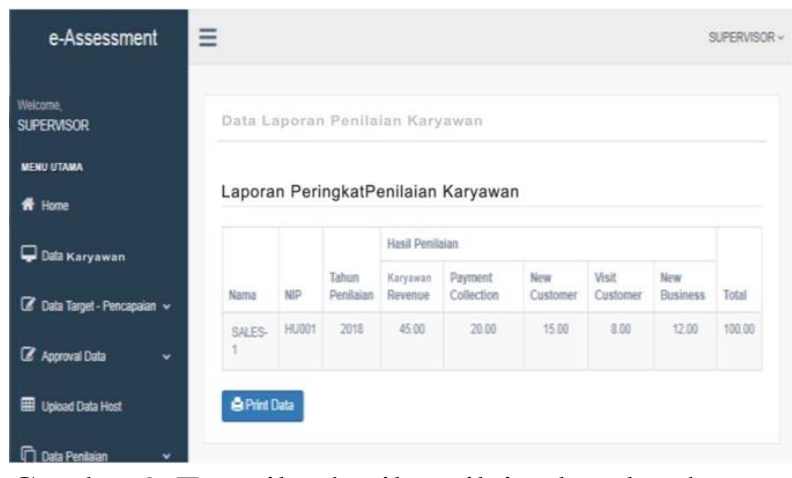

Gambar 9. Tampilan hasil penilaian keseluruhan karyawan 
Tampilan halaman ini, memberikan informasi mengenai laporan dari kinerja karyawan yang disusun berdasarkan nilai tertinggi sampai nilai terendah, laporan peringkat penilaian karyawan ini hanya dapat dibuka oleh supervisor dan manager.

\section{Kesimpulan}

Berdasarkan hasil rekayasa perangkat lunak dan implementasi yang telah dilakukan, dapat diambil kesimpulan sebagai berikut: Penerapan rekayasa perangkat lunak Key Performance Indicator untuk penilaian kinerja karyawan menggunakan metode Simple Additive Weighting dapat mengefisiensi waktu proses penilaian dalam penentuan peringkat kualitas kinerja karyawan. Hasil pengujian black box pada aspek fungsionalitas perangkat lunak menunjukkan bahwa setiap fungsi pada perangkat lunak dapat berjalan sesuai fungsinya. Penggunaan perangkat lunak ini dapat meningkatkan efisiensi proses pembuatan laporan penilaian sebesar 57.14\%. Pada sistem berjalan membutuhkan 7 tahapan sedangkan pada penggunaan rekayasa perangkat lunak ini dapat mengefisiensi menjadi 3 tahapan.

\section{Saran}

Mengamati dan mempertimbangkan fungsi dan manfaat rekayasa perangkat lunak kami memiliki beberapa saran dalam mengembangkan sistem informasi ini. Adapun saran dari hasil penelitian ini diantaranya adalah:

a. Pengoptimalan manfaat rekayasa perangkat lunak ini dapat dilengkapi melalui sinkronisasidengan sistem yang telah ada pada perusahaan tersebut sehingga database yang ada dapat menjadi satu kesatuan.

b. Berhubungan dengan perkembangan teknologi dan kebutuhan akan informasi yang sangat pesat diharapkan agar dapat mengembangkan sistem dalam platform aplikasi lain nya seperti berbasis android maupun berbasis desktop.

\section{Referensi}

Kadir, A. (2017). Dasar Logika Pemrograman Komputer. Jakarta: PT Elex Media Komputindo.

Latif, L. A. (2018). Buku Ajar: Sistem Pendukung Keputusan Teori dan Implementasi. Yogyakarta: Penerbit Deepublish.

Moeheriono. (2012). Pengukuran Kinerja Berbasis Kompetensi. Jakarta: Raja Grafindo Persada.
Mulyani, \& sri. (2016). Metode Analisis Dan Perancangan Sistem. Bandung: Abdi Sistematika.

Muslihudin, M., \& Oktafianto. (2016). Analisis Dan Perancangan Sistem Informasi Menggunakan Model Terstruktur Dan UML. Yogyakarta: $C V$ Andi Offset.

Pratala, C. T., Asyer, E. M., Prayudi, I., \& Saifudin, A. (2020). Pengujian White Box pada Aplikasi Cash Flow Berbasis Android Menggunakan Teknik Basis Path. Jurnal Informatika Universitas Pamulang, 5(2), 111-119. doi:informatika.v5i2.4713

Rinianty, \& Sukardi. (2018). Sistem Pendukung Keputusan Penerimaan Karyawan Mengunakan Metode SAW Pada CV. Green Advertising.

Sari, \& Febrina. (2018). Metode Dalam Pengambilan Keputusan. Yogyakarta: Penerbit Deepublish.

Soemohadiwidjojo, A. (2015). Panduan Praktis Menyusun KPI. Jakarta: Penebar Swadaya.

Utama, I. G. (2016). Pengantar Industri Pariwisata. Yogyakarta: Penerbit Deepublish.

Wicaksono, S. (2017). Rekayasa Perangkat Lunak. Malang: Seribu bintang.

Yulistina, S. R., Nurmala, T., Supriawan, R. M., Juni, S. H., \& Saifudin, A. (2020). Penerapan Teknik Boundary Value Analysis untuk Pengujian Aplikasi Penjualan Menggunakan Metode Black Box Testing. Jurnal Informatika Universitas Pamulang, 5(2), 129-135. doi:10.32493/informatika.v5i2.5366 